\title{
Teaching English-Yoruba Prosodies in Context: Connectivity in Disparity
}

\author{
Atolagbe, Adebukunola A. ${ }^{1}$ \\ ${ }^{1}$ Lagos State University, Nigeria \\ Correspondence: Atolagbe, Adebukunola A., Lecturer in English, Lagos State University, Lagos, Nigeria. E-mail: \\ bukolaatol@yahoo.com
}

Received: December 11, 2013 Accepted: April 8, 2014 Online Published: May 4, 2014

doi:10.5430/ijelt.v1n2p28 URL: http://dx.doi.org/10.5430/ijelt.v1n2p28

\begin{abstract}
The paper discusses a core feature that differentiates Nigerian English from other native Standard English varieties, namely the English prosodies of Stress-Rhythm-Intonation, in the light of the dominant L2 transfer feature of Nigerian spoken English's Yoruba 'tone-prominence'. Particular attention is given to Pitch which translates phonetically into Yoruba 'Tones'.

It discusses how the language use of popular street urchins in Lagos, Nigeria (popularly called 'Area boys') has been successfully used (among other registers) to teach the English prosodies of stress (embedding 'pitch'), Rhythm and Intonation (also embedding 'pitch') in a multilingual but largely Yoruba L2 'tone-prominence' speech community.

A prosodic theoretical framework is adopted in the discussions and analysisof data, hitherto used in teaching a graduating class of B.A. English students who had been taught courses in English phonology throughout their four year course. It is argued that despite the disparity between the two language systems of Yoruba and English at the prosodic level, the language of 'Lagos Area Boys' creates some connectivity which the typical undergraduate student of English can identify with and which is used to successfully teach Pitch in particular, even though that language register is largely 'tone-prominence' based. Moving from the known to the unknown is always a useful teaching methodology and this approach has been employed here. Thus, an established connectivity in disparity can and indeed has, been used successfully within the Yoruba-English L2 language contact situation.
\end{abstract}

Keywords: English-Yoruba Prosodies, Teaching, Connectivity, Disparity

\section{Introduction}

Teaching English Phonology at tertiary level to non-native speakers of English, for about two decades, and particularly in a non-native speaker (L2) environment, has shown that many students and teachers of English find the learning and teaching of English suprasegments or prosodies quite challenging. This fact is particularly so because the mechanical devices needed to aid learning are practically not available and there has to be a lot of improvisation by the teacher, who must himself or herself be a fairly good role model (if not a native speaker) to be emulated.

Many Yoruba students understand, can identify and can use fairly well, English stress, rhythm and intonation, when they are properly taught. However, many Yoruba students do not understand 'pitch' or its place in English speech; they often confuse level and moving/fluctuating pitch with tones, and this is expectedly so because Yoruba language characteristically employs pitch as tones and not as intonation, like we have in English.

In an attempt to effectively teach 'pitch' in particular, as a suprasegment of English, apart from stress, rhythm and intonation - which are three distinct suprasegments, unlike pitch which is embedded in stress and which translates to intonation when it fluctuates - a simple research was carried out, and the results are presented in the following sections: Introduction, Objectives, Theoretical Background, Research Methodology, the English Prosodies and the Yoruba Prosodies, Data Analysis and Findings, Discussion and Conclusion.

\subsection{Objectives}

This research was carried out with the following objectives: 
i. To find out if our subjects - four hundred level students of the English department, Lagos State University (graduating class) understand 'pitch' (can identify/understand/use it) in speech;

ii. To explore the benefits of contrastive analysis in effectively teaching 'pitch', as a suprasegment of English, by connecting the disparity in the Yoruba prosodic system and the English prosodic system, pitch being a less taught suprasegment in Nigerian schools, unlike stress and intonation.

iii. To find out if our subjects have acquired enough English phonology at this level, to speak or understand English intelligibly, both nationally and internationally.

\subsection{Theoretical Framework}

Pitch' is a prosody or suprasegment and so a prosodic approach should be employed in an empirical research of this nature. In other words, underlying this study are: principles and insights from geometric or non-linear phonology which consider 'spreading rules' (Donna Jo Napoli, 1996: 90) 'where the features associated with a given segment spread so that they become associated with another nearby segment as well' and autosegmental theories of phonology 'which consider features as somehow independent of segments (any phonetic feature being potentially an auto segment). These theories become useful in the light of the contrastive focus on Yoruba tones which are discreet, unlike English pitch and intonation which are spread over stretches of utterances, not merely segments and are therefore non-discreet.

Thus, even though pitch can be identified as a feature that differentiates speech sounds, apart from the intrinsic quality of phonemes (speech sounds or segments) which are derived from their articulatory, auditory and acoustic properties, pitch must be considered more as a feature that spreads over more than a segment, syllable or word, hence we talk of PITCH CONTOUR or INTONATION CONTOUR and thereby, pitch as a suprasegmental feature. Pitch can be level or steady and could therefore be high, mid or low in rapid or connected speech, just as in music.

On the other hand, pitch can fluctuate, can move up and down (fluctuating between high and low or vice-versa) over a stretch of utterance, and therefore be regarded as intonation. Pitch is measured in cycles per seconds (in hertz), or relative frequencies (according to the motion that occurs in the vocal folds). Since the oscillation in the vocal chords or vocal folds of females is usually faster than that of males, (an average of 360 cycles per second as opposed to 280 cycles per second for males) the pitch of women is generally higher than the pitch of men. Pitch can be heard as the quality of highness or lowness in the human voice, but this is generally relative, since a very high pitch to speaker A may just be a high pitch (or even normal pitch) to speaker B. Nevertheless, one can relatively say when a high, mid or low pitch is being used in a spoken text or in an utterance.

It must be emphasized that Pitch marks different 'speech types'. For example, sports commentary (generally racy and high pitched) differs from a news broadcast (steady, normal but fluctuating pitch) or even from a normal conversation or class lecture. Diagrammatically, pitch can not be easily represented linearly on paper or in bar charts, like in stress patterns, except in spectrograms. However, Pitch is a recognizable feature of speech.

\section{Research Methodology}

This empirical research was conducted with a population of sixty seven students, out of which sixty students who were present in two consecutive classes (of lecture periods) formed the sample size. A midget cassette recorder/player was used to gather data of about ten minutes of connected speech which was played back to the class of sixty students. Questionnaires were also used as primary instruments of the research, and were administered to the students before and after listening to the data.

The questionnaire had questions that were meant to elicit Yes or No responses, gradable options as choices, as well as open-ended responses. The various responses from the subjects were calculated in simple percentages, frequencies of occurrences and simple ratios. The results are presented and discussed in subsequent sections below.

Three male representatives of the subjects (students) were instructed on how to gather the data from conversations of street urchins ('area boys') at motor parks or bus stations. Getting the data surreptitiously without molestation from the area boys was almost impossible at first. That accounts for the quantity and volume of what was recorded and used as data.The researcher had to mimic what was expected in a two minute initial recording as example. All the recorded texts from the three male students therefore formed the data played back to the students in the second lecture, where the students answered only the final questions, 10-12, which sought to evaluate their knowledge of 'pitch' after the exposure to the data; other questions were answered in the first lecture, pre-data exposure. The students study in an environment where the native language is Yoruba and most of them are Yorubas. 


\section{Discussion: English and Yoruba Prosodies}

English language exhibits features of spoken language which are spread over stretches of utterances to express linguistic and affective meanings; these features are non-discreet like the phonemes or segments, and are called prosodies or suprasegments/suprasegmentaIs. They include 'stress', 'pitch', 'rhythm' and 'intonation'. Other suprasegments which are however not always acknowledged by most phoneticians or phonologists include 'Tempo' or 'Speed', 'Pause' or 'Juncture', 'Intensity' (loudness), 'length' (duration) and 'melody' (otherwise called 'Intonation') as discussed in Atolagbe (1999: 130 ff). A combination of these' suprasegments could make an otherwise normal speech or utterance sound emotional (remorseful or non-challant as the case may be), or suggest an 'accent' of speech (such as educated, elitist or low class).

While word stress and sentence stress point out the centre of information in a sentence when combined effectively with intonation, rhythm (achieved through' the alternation 'of stressed and unstressed syllables) gives English its characteristic accent, apart from its aesthetic and literary functions. Pitch however, characterizes speech types, such that one can identify baby talk as distinct from adult talk, due to differences in pitch levels. Also, the pitch used for sports commentary is usually higher than that used in normal conversation or for news broadcast; for example a normal pitch, used for a political campaign would be inappropriate, as a high pitched voice would be more effective.

Pitch usage in this regard refers to the general level of pitch maintained throughout the speech, as opposed to the pitch contours or intonation patterns attached to the sentences that make up the speech, and which certainly convey grammatical or attitudinal meanings. For instance, 'Mary passed' said on a high pitch would suggest an excited speaker, unlike 'Mary passed' on a relatively low pitch, which could suggest shock or disgust at the fact that Mary passed. The same sentence said on a falling tone would be taken as a statement while the same sentence spoken with a rising intonation would be regarded as a question.

In contrast to English language, Yoruba language on the other hand does not have stress, the feature that makes a syllable or word stand out as more prominent than its neighbours, through the use of a combination of pitch + length/duration + loudness/intensity. Rather, Yoruba employs - 'prominence', such that each syllable enjoys relatively, the same degree of prominence. Neither does Yoruba utilize intonation (fluctuating pitch over utterances), but tones (relative degrees of level or moving pitch, attached to individual segments, syllables or words) and a spreading of these tones geometrically, to create pitch fluctuations in sentences.

Thus, the phonological system of Yoruba can be represented thus:

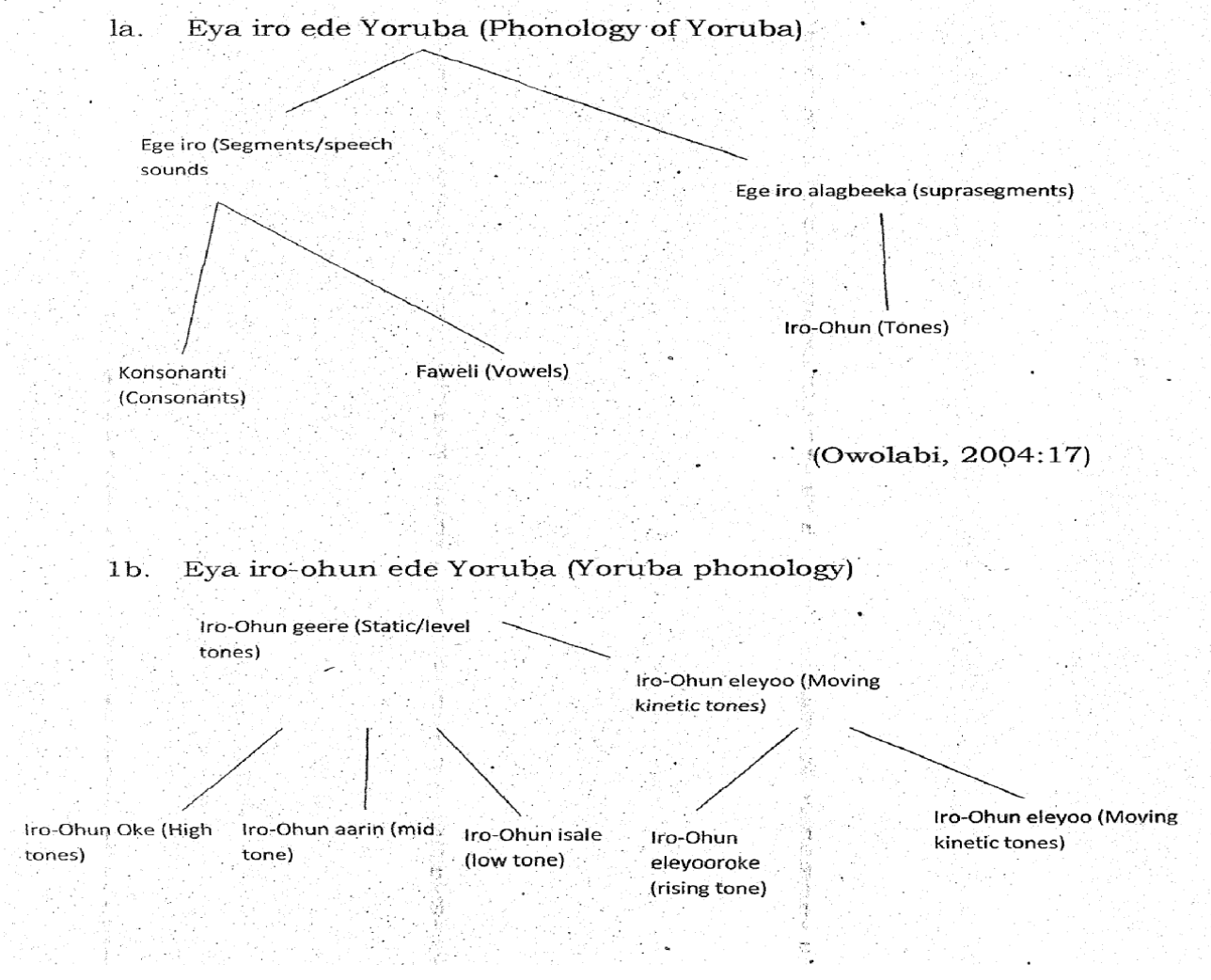


Educated Yoruba speakers of English often find it difficult to differentiate English pitch from Yoruba tone since Yoruba tones appear to be the phonetic correlates of English pitch, as far as they are concerned (this researcher, being Yoruba by ethnicity as well). Thus, pitch as a distinct suprasegment of English proves to be a difficult concept to comprehend.

Street urchins in Lagos, Nigeria, who are known as 'area boys', constitute a nuisance to the citizens, especially at motor parks or bus stations. They congregate in groups of two or more, extorting money from private bus drivers and sometimes passengers, at bus stops or bus stations, terrifying people when it gets dark and often times engaging in street brawls. They have developed their own language register in the last five to ten years; a register characterized by the following features: a very deep voice or relatively low pitch or else a very high pitch, which they often mimick forcefully, a loud volume or intensity, racy language, plenty of slangs, especially lexical terms for common nouns/nominals and verbs such as the Naira denominations (e.g. 'Fiber', 'shandy', 'Bros', 'parrow lo', etc.) in addition to certain peculiar gesticulations. They could be dressed roughly - in singlets/ dirty Tee - shirts and jeans or they could be normally dressed and not easily identified as ruffians.

An encounter with an 'area boy' at a bus stop or bus station could be quite unpleasant if one does not do their bidding and promptly too, especially parting with some little amount of money. For an unwary pedestrian or commuter to easily recognize them, they switch from 'normal discourse tone' to their language register identified and described above. Most residents of Lagos are familiar with such speech, which even comedians mimick on television, and students of English at the Lagos State University are also familiar with such language use, particularly since most of the students are either Yoruba themselves or understand Yoruba - the language normally spoken by these area boys (or pidgin English).

The use of this unique but interesting language register of Lagos street urchins, which employs Yoruba speech features and pitch usage with dexterity, was therefore seen as a good resource in teaching pitch (especially in English) to a current graduating class of students of English in a second language leaning situation.

\section{Results}

The results of answers from the questions, as given by the sixty students sampled are reported below in four sections. Questions 1-3 requested for the name, college year (level) and ethnic affiliation, languages spoken by the respondents and these are reported in section 4.1. Questions 4-8 sought to find out and evaluate how much time they had spent learning English phonology and how much of it they had so far acquired. These are reported in section 4.2. Question 9 specifically sought to find out their understanding of the term 'pitch' prior to the students exposure to and explanations of the data. This is explained in section 4.3. Lastly, section 4.4 presents the results from their self assessment of their understanding of pitch after exposure to the data and their attempt to re-define 'pitch'.

\subsection{Students Bio-data}

All the students had spent at least three sessions as students in the English department of the Lagos State University, Lagos, Nigeria and were in their final year, four hundred level. While fifty-nine students wrote their personal names or matriculation/registration numbers, one person did not include either his/her name or registration number, for personal reasons. Forty-nine were Yoruba while eleven were non Yorubas. However, fifty-seven understood Yoruba. This means that $81.66 \%$ were Yoruba and 95\% understood Yoruba. So, only a minority if any at all, would not have been familiar with how or what the street urchins (area boys) say when they talk, as all the respondents come across them when they commute to and from school (a non- residential University).

\subsection{Knowledge of English Phonology}

Table 1. Liking for English phonology (question 5)

\begin{tabular}{llll}
\hline Result & Yes & No & Total \\
\hline Frequency & 54 & 6 & 60 \\
\hline Percentage & $90 \%$ & $10 \%$ & $100 \%$ \\
\hline
\end{tabular}


Table 2. I can now speak English intelligibly internationally /nationality (Question 6)

\begin{tabular}{lllll}
\hline Result & Yes & No & Don't know & Total \\
\hline Frequency & 31 & 20 & 09 & 60 \\
\hline Percentage & $51.66 \%$ & $33.33 \%$ & $15 \%$ & $99.99 \%$ \\
\hline
\end{tabular}

Table 3. Students knowledge of English Language Phonology (Questions 7 \& 8)

\begin{tabular}{lllll}
\hline Result & Poor & Fair & Good & Total \\
\hline Frequency & 04 & 39 & 17 & 60 \\
\hline Percentage & $6.66 \%$ & $65 \%$ & $28.33 \%$ & $99.99 \%$ \\
\hline
\end{tabular}

\subsection{Knowledge of Pitch Prior to Data Exposure}

The answers given by the students, to the definition of 'pitch' were graded by the researcher, as 'poor, fair, good' and presented below.

Table 4. Prior Understanding of Pitch (Question 9)

\begin{tabular}{llllll}
\hline Result & No response & Poor & Fair & Good & Total \\
\hline Frequency & 1 & 10 & 32 & 17 & 60 \\
\hline Percentage & $1.66 \%$ & $16.66 \%$ & $53.33 \%$ & $28.33 \%$ & $99.98 \%$ \\
\hline
\end{tabular}

\subsection{Understanding of 'Pitch' Post Data Exposure}

The answers given by the students to the definition of pitch after exposing them to the data and providing explanations to the data, were also graded as 'poor, fair, good', considering their comments/self assessment of whether their exposure to the data was of any help in providing a better understanding of the concept under study: PITCH.

Table 5. Understanding of Pitch post-data exposure (Questions 10-12)

\begin{tabular}{llllll}
\hline Result & No response & Poor & Fair & Good & Total \\
\hline Frequency & 5 & 1 & 28 & 26 & 60 \\
\hline Percentage & $8.33 \%$ & $1.66 \%$ & $46.66 \%$ & $43.33 \%$ & $99.98 \%$ \\
\hline
\end{tabular}

\subsection{Summary of Findings}

From the results gathered and presented above, one observes the following:

1. $90 \%$ of the students like phonology while $10 \%$ do not.

2. Despite taking phonology courses for between four to six semesters, only $51.66 \%$ of the students are confident that they can speak and understand English speech quite well, whether locally or internationally; $33.33 \%$ stated categorically that they had not acquired enough competence while $15 \%$ were not sure.

3. Despite the position in observation (2) above, over $65 \%$ of the students appear to have a fair understanding of English phonology (table 3 results).

4. Also, more than $53.33 \%$ of the subjects were able to define Pitch relatively well. This was probably due to the fact that this had been taught and defined in previous years and earlier courses, at 200 and 300 levels (table 4 results).

5. Interestingly, the total of 'Good' and 'Fair' definitions of 'Pitch' prior to the use of the data and the total of 'Good' and 'Fair' definitions of Pitch' after exposure to the data - the speech of 'Area boys' '(street urchins) - was $81.66 \%$ and $89.99 \%$ respectively. This shows a slightly better performance and response 
after the use of the data, particularly because the 'poor' responses prior exposure dropped from $16.66 \%$ to $1.66 \%$ after exposure to the data. Also, most of the responses of individual subjects (as poor/fair/good) either improved (to fair/good respectively) or else remained the same for the majority of the subjects.

Except for respondent 14 whose performance/response after exposure to the data was worse, and five others, who did not respond by defining 'Pitch' after the use of the data (subjects: 4,7,10,57,60) all other respondents gave about the same definitions again or slightly better explanations.

It is noteworthy that the data affected their understanding of 'Pitch' positively as far as fifty-four out of the sixty students were concerned, while five gave no response and one said it had a negative effect- probably got him or her more confused.

Again some comments of the students were quite interesting and notable, such as the following:

Respondent 3: In Yoruba, I realize that suprasegments are easier to know and understand.

Respondent 14: It takes a native speaker to observe all of the suprasegments of English.

Respondent 20: The pitch is very high with a fast speed/tempo and the intonation marker marks it as an informal speech.

Respondent 22

Respondent 28:

I have been able to identify the differences between pitch, loudness and tempo in speech. Through the pitch, one tends to understand how pitch operates in English.

Respondent 31: The pitch of the area boys is quite different from any formal conversation.

Respondent 21: Respondent 28: The recorded speech of the area boys (riffraffs) give or show the effect of pitch. Through the pitch, one tends to understand how pitch operates in English.

Respondent 46: I am really happy I didn't miss out in today's class; thank you madam.

\section{Conclusion}

It has been observed that about half of the class of students which served as subjects in this research, had a theoretical knowledge of 'Pitch' which they probably memorized from lecture notes or reference materials. An exploitation of the contrasts between their native mother tongue (Yoruba) and the target language (English) at the prosodic level provided the practical lesson that explained 'Pitch' in English in a better and more realistic manner.

Even though the students could not immediately re-define pitch after the entire exercise (just five minutes after the second lecture where the data was used), an overwhelming majority of them were certain that they had been positively imparted by the exercise.

Thus, we were able to discover how much knowledge of English phonology and 'Pitch' in particular that the students had; we also explored the contrastive prosodic systems in both languages, positively (connecting disparity), and we were able to improvise practical teaching where audio-lingual facilities were lacking. Certainly, such efforts must be reinforced to achieve maximum results in effectively teaching English phonology in non native speaker, $\mathrm{L}_{2}$ environments.

\section{References}

Adeniyi, H., \& Atolagbe, A. A. (2004). Vowel harmony in English: A non-linear approach. In S. Awonusi, \& E. A. Babalola (Eds.), The domestication of English in Nigeria: A festchrift in honour of Abiodun Adetugbo. Lagos: University of Lagos Press. pp. 114-127.

Atolagbe, A. A. (2000). Elementary phonological analysis: A course text for tertiary schools. Lagos: Jehovah Shammah.

Atolagbe, A. A. (1999). A re-examination of English suprasegments.In Olorunleke, O., \& L. Ladele (Eds.), Newperspectives in linguistics and literature. Lagos Ilu project associates. pp. 130-138.

Awonusi, Segun. (2009). Coping with English pronunciation ( $2^{\text {nd }}$ ed.). Lagos: Sam Iroanusi publications.

Carr, P. (1993). Phonology. New York St. Martin's press.

Dunstan, E. (1969). Twelve Nigerian languages. London: Longmans, Green \&co. 1td.

Gimson, A.C. (1980). An Introduction to the pronunciation of English (3rd ed.). Great Britain: Edward Arnold. 
Jo Napoli, D. (1996). Linguistics. New York, Oxford; Universitypress.

Ogbulugo, C. (2001). The phonology of English. In Fakoya, A.A., \& S.A.Ogunpitan (eds), English Compendium, Vol. 3 \& 4. Lagos: Department of English, Lagos State University. pp. 1-23.

Owolabi K. (2004). Ijinle Itupale Ede Yoruba (1): Fonetiiki ati fonoloji. Ibadan: Onibonojé press \& book industries (Nig.) ltd.

Thorne, S. (2008). Mastering advanced English language ( $2^{\text {nd }}$ ed.). New York: Palgrave Macmillan.

Williams, D. (1990). English language teaching: An Integrated approach. Ibadan: Spectrum books. 